\title{
Wind and Energy Markets: A Case Study of Texas
}

\author{
Ross Baldick, Fellow, IEEE
}

\begin{abstract}
Many jurisdictions worldwide are greatly increasing the amount of wind production, with the expectation that increasing renewables will cost-effectively reduce greenhouse emissions. This paper discusses the interaction of increasing wind, transmission constraints, renewable credits, wind and demand correlation, intermittency, carbon prices, and electricity market prices using the particular example of the Electric Reliability Council of Texas market. An estimate is made of the cost of using wind to mitigate greenhouse gas emissions.
\end{abstract}

Index Terms-Electricity markets, greenhouse emissions, wind integration.

\section{INTRODUCTION}

I $\mathrm{N}$ THE LAST decade, there has been a great increase in the amount of renewables, particularly wind power, in the United States, with the highest amounts of wind generation in the states of Texas, Iowa, California, Oregon, Washington, and Oklahoma. Wind power has also grown rapidly in other countries, including those of Europe and also in Australia. There are undoubtedly several policy drivers for this global expansion of wind; however, the most widespread is to respond to the need to reduce greenhouse gas emissions. That is, the implicit assumption is that encouraging wind is a cost-effective way to reduce greenhouse emissions.

This paper explores the interaction of various issues to try to understand the implications of the policy to increase wind in the United States. In particular, this paper examines the interaction of increasing wind, transmission constraints, renewable credits, wind and demand correlation, intermittency, carbon prices, and electricity market prices using the particular example of the Electric Reliability Council of Texas (ERCOT) market. The analysis aims at estimating the cost of using wind power to mitigate greenhouse gas emissions.

In many respects, ERCOT is a leading indicator of the likely effects of wind since it has the highest penetration of wind in the United States, has a well-functioning wholesale market where energy is valued based on marginal offers, and unlike the Western and Eastern Interconnections of the United States and countries such as Spain, ERCOT has very little hydroelectric capacity to provide storage and flexibility in the face of wind intermittency. Concerns that arise in ERCOT may also eventually be problematic in other areas.

Manuscript received August 27, 2010; revised February 17, 2011; accepted May 25, 2011. Date of publication September 1, 2011; date of current version February 23, 2012. A shorter version of this paper previously appeared as a United States Association for Energy Economics Dialogue, vol. 18, no. 2, 2010, available at http://dialogue.usaee.org.

The author is with the Department of Electrical and Computer Engineering, University of Texas, Austin, TX 78712 USA (e-mail: baldick@ece.utexas.edu).

Color versions of one or more of the figures in this paper are available online at http://ieeexplore.ieee.org.

Digital Object Identifier 10.1109/JSYST.2011.2162798
The rest of this paper is organized as follows. Section II begins with a description of offer-based economic dispatch in U.S. markets, focusing on the particular context of realtime markets using a very simple example involving wind. Section III expands on the example by introducing transmission limitations. Section IV discusses the effect of U.S. production tax credits and renewable energy credits. The example helps to interpret ERCOT empirical data. Section V considers transmission price risk and transmission construction. Section VI focuses on wind and demand correlation and intermittency. Section VII puts together the various costs and estimates the cost of reducing carbon emissions with wind. Section VIII concludes with some policy implications.

\section{OFFER-BASED ECONOMIC DISPATCH}

In so-called "organized" markets in the United States, the process of offer-based economic dispatch by the independent system operator (ISO) determines the choice of which generators meet the electric demand [1]. As a stylized example of this process, generators offer to sell:

1) energy;

2) reserves and other ancillary services (AS);

and the ISO selects the offers to meet demand. Typically, there are at least two timeframes for this process:

1) "day-ahead," technically a short-term forward market to put in place obligations for tomorrow, based on anticipation;

2) "real-time," using short-term (several minutes) forecasts of actual demand and other system conditions.

This paper will focus on the real-time energy market, ignoring the day-ahead market and ignoring the AS market since:

1) the real-time market will illustrate the main issues;

2) ERCOT has only recently established a centralized dayahead market (as of December 2010);

3) wind generators are unlikely to offer reserves and may choose not to participate in the day-ahead market.

However, the implications of the need for AS to support wind production will be discussed briefly.

In offer-based economic dispatch, an offer by a generator is a specification of the minimum price it is willing to receive to produce versus the quantity of production. An offer applies for a particular hour or range of hours. To simplify our discussion, we will consider a particular hour, ignoring intrahour variations, and will consider a particular type of offer, namely a "block" offer. Specification of a block offer requires a quantity and a price and can be interpreted as an offer:

1) to generate at any level up to maximum power in the block in MW; 


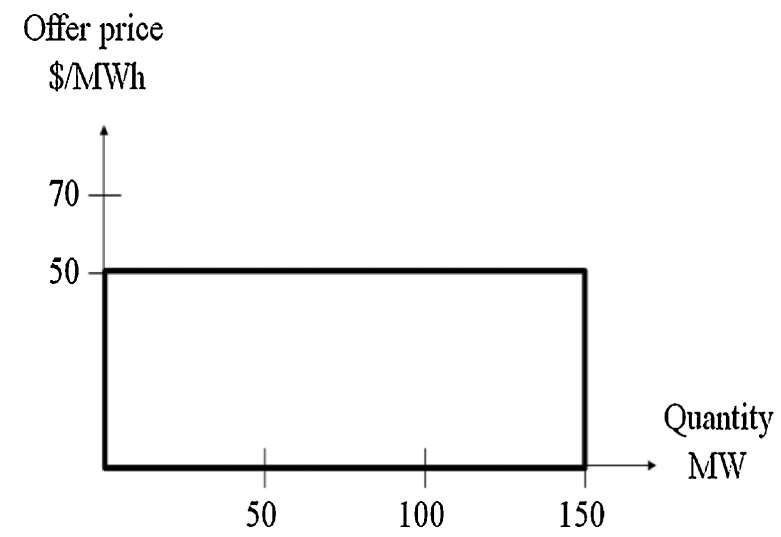

Fig. 1. Block offer.

2) for remuneration at least equal to the nominated price in $\$ / M W h$.

Fig. 1 shows an example block offer for $150 \mathrm{MW}$ at a price of $\$ 50 / \mathrm{MWh}$. The ISO receives offers from the various generators in the market and then selects amongst the offers to meet its short-term forecast of demand based on the offer prices. As a general principle, the ISO uses an offer with a lower offer price in preference to a higher offer price. Examples of such markets are the "organized markets" of the Northeast U.S. (PJM [2], ISO-NE [3], NYISO [4]), Midwest [5], California [6], Southwest Power Pool [7], and Texas (ERCOT) [8]. Other markets throughout the world, such as the Spanish market [9] and the Australian market [10], are broadly similar but have some particular differences.

A significant issue for market participants is the model of price formation; that is, the rule under which prices are set. In these markets, roughly speaking, the highest accepted offer price or, equivalently, the offer price that would serve an additional MW of demand, sets the price for all energy sold. This description is somewhat loose and a more careful definition is needed if, for example, there are insufficient offers to meet demand, the demand is at a jump in prices between blocks, and in the case of limiting transmission constraints ("congestion") [1].

To illustrate the operation of a real-time market that includes wind resources, we will consider a very simple example system. The transmission in this system consists of just two lines joining three "buses," M, W, and N, which are the points of interconnection between generators, transmission lines, and substations that serve demand. This topology simplifies the situation compared to reality, but is useful as a start.

Although some market designs do not allow or do not require wind to make explicit offers, we will assume that wind generators offer into the market. Moreover, in the ERCOT zonal market in place until December 2010, bids and offers represented deviations from "balanced schedules" that specify the generation and the corresponding load [11]. For the purposes of our discussion, however, we can consider hypothetical offers by wind that are equivalent to the combined effect of the schedule and the actual bids and offers.

Wind (at buses $\mathrm{M}$ and $\mathrm{W}$ ) and thermal (at buses $\mathrm{W}$ and $\mathrm{N}$ ) submit block offers into the real-time market to meet $1500 \mathrm{MW}$

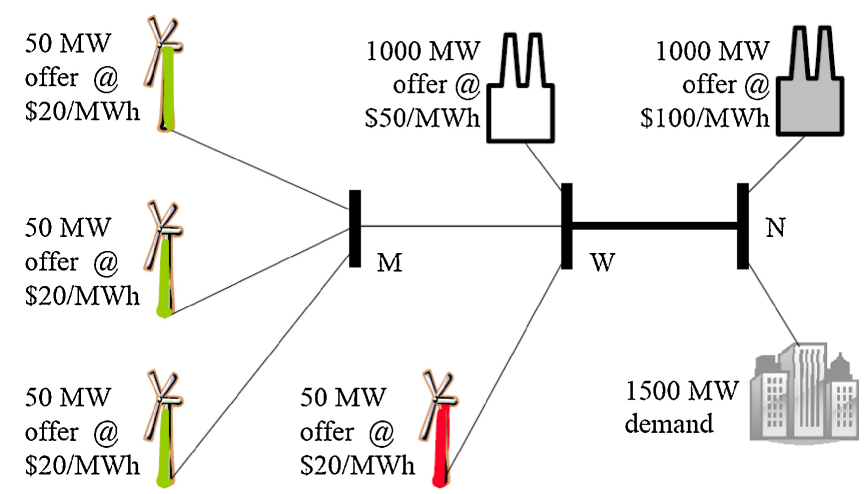

Fig. 2. Example with unlimited transmission, $1500 \mathrm{MW}$ demand at $\mathrm{N}$, and block offers.

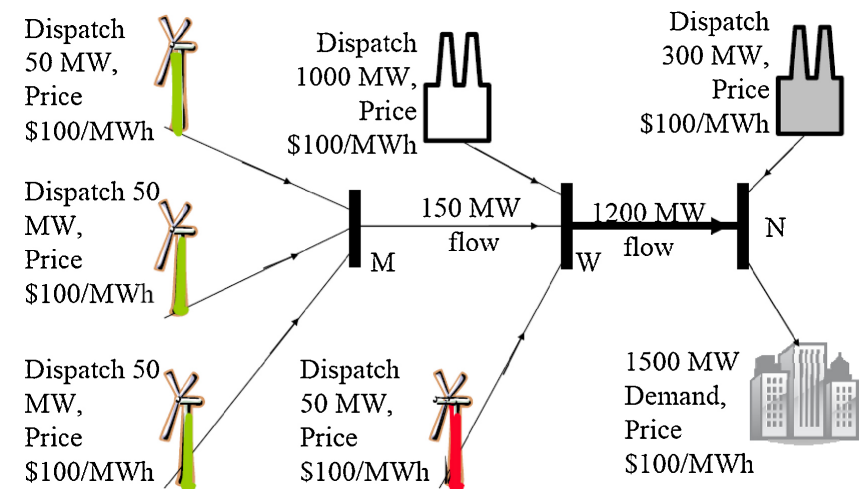

Fig. 3. Dispatch and prices for $1500 \mathrm{MW}$ demand, unlimited transmission capacity.

of demand (at N). To distinguish between the various generators, the wind farms at $\mathrm{M}$ will be called the "green" wind farms, the wind farm at W will be called the "red" wind farm, the thermal generator at $\mathrm{W}$ will be called the "white" generator, and the thermal generator at $\mathrm{N}$ will be called the "gray" generator. The offer prices are illustrated in Fig. 2: wind offers at the lowest price of $\$ 20 / \mathrm{MWh}$, then the "white" thermal at $\$ 50 / \mathrm{MWh}$, and then the "gray" thermal at \$100/MWh. We will first consider unlimited transmission in this section and then consider limited transmission in Section III.

To meet demand on the basis of using lower offer priced generation in preference to higher offer priced generation, all $200 \mathrm{MW}$ of available wind generation, $1000 \mathrm{MW}$ of "white" thermal, and $300 \mathrm{MW}$ of "gray" thermal generation are required. Amongst the dispatched generation, the highest accepted offer price was $\$ 100 / \mathrm{MWh}$ from the "gray" thermal generator at bus $\mathrm{N}$. Note that to serve an additional MW of demand at any bus it would be necessary to use an additional MW of "gray" generation. The "green" and "red" wind and the "white" thermal generator are all fully dispatched. The situation is illustrated in Fig. 3, and to summarize, the price paid to all generators and paid by demand is $\$ 100 / \mathrm{MWh}$.

\section{TRANSMISSION LIMITATIONS}

In practice, limitations on transmission capacity can limit the flexibility of the ISO to dispatch from the lowest priced 


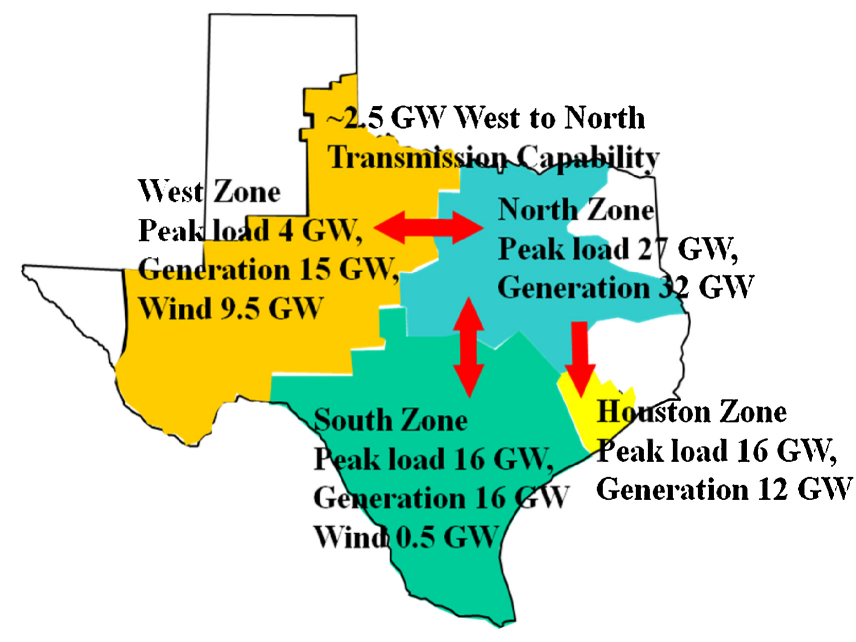

Fig. 4. ERCOT zones and approximate peak load and generation capacity levels. Source: based on [12].

offers. If the limited capacity of transmission prevents the use of an offer with a lower price then the highest accepted offer can be thought of as varying with the location of the bus. So-called "nodal" or "locational marginal prices" reflect this variation. Roughly speaking, the price at each bus is based on the offer price to meet an additional MW of demand at that bus. In the ERCOT market until December 2010 [11], [12] and in the Australian market [13], there is a coarser "zonal" representation of transmission. For example, the zones in the ERCOT zonal market are illustrated in Fig. 4. Peak load in ERCOT is around $65 \mathrm{GW}$, with generation capacity around $75 \mathrm{GW}$.

From Fig. 4, it is clear that the wind is predominantly in the West Zone. The transmission capability from the West to the North Zone varies but is on the order of $2.5 \mathrm{GW}$. This West to North capability does not translate directly into an export capability because of the sharing of flows on lines according to Kirchhoff's laws. However, the West Zone export capability is less than the West Zone wind generation capacity. These stylized facts will be represented into the example to qualitatively understand the effects of transmission constraints.

In particular, we will now assume that there is only $100 \mathrm{MW}$ of transmission capability from bus $\mathrm{M}$ to bus $\mathrm{W}$ and only $1000 \mathrm{MW}$ of transmission capability from bus W to bus N. Optimal dispatch now involves only $100 \mathrm{MW}$ of production in total from the three "green" wind farms, $50 \mathrm{MW}$ from the "red" wind farm, $850 \mathrm{MW}$ from the "white" thermal generation, and $500 \mathrm{MW}$ from the "gray" thermal generation. The presence of transmission constraints has necessitated less use of low offer price resources and more use of higher offer price resources.

Again, the highest accepted offer price was $\$ 100 / \mathrm{MWh}$ from the "gray" thermal generator at bus $\mathrm{N}$, but this no longer determines the price at the other buses because of the transmission limitations. While the "red" wind was fully dispatched at bus W, the "white" thermal generator at bus W was not fully dispatched. Moreover, the "green" wind farms at bus $\mathrm{M}$ were not fully dispatched.

Since the wind farms are not generating at their full potential, they have been curtailed. Since the process is the

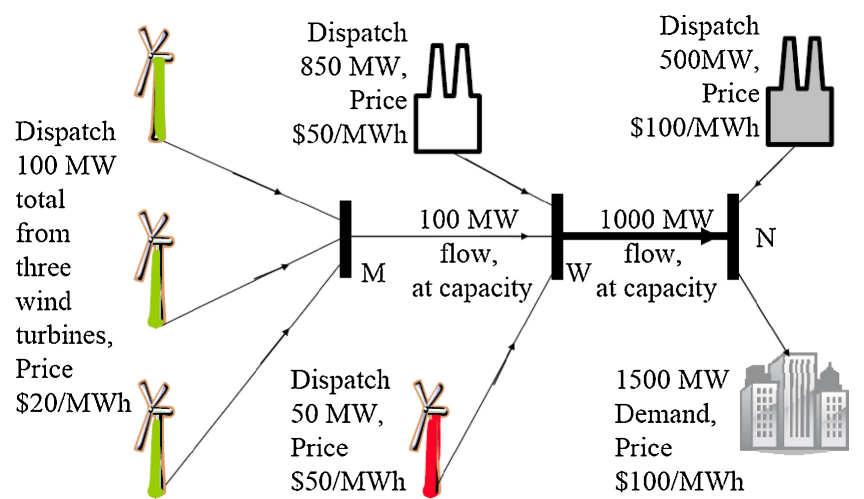

Fig. 5. Dispatch and prices with limited transmission.

result of a market-based process, we might refer to this as "economic curtailment" to distinguish it from, for example, a quantity rationing basis where the ISO decides on the amount of generation without (direct) reference to bids and offers. For example, until the advent of the ERCOT nodal market in December 2010, wind curtailment in ERCOT due to intrazonal transmission limitations has typically been on the basis of quantity rationing rather than economic rationing; however, in this paper we will focus on economic rationing.

To translate the observations about dispatch into the LMPs, denote the LMPs at buses $\mathrm{N}, \mathrm{W}$, and $\mathrm{M}$, by $\mathrm{LMP}_{\mathrm{N}}, \mathrm{LMP}_{\mathrm{W}}$, and $\mathrm{LMP}_{\mathrm{M}}$, respectively. Now note that:

1) to meet an additional MW of demand at N, we would dispatch an additional MW of $\$ 100 / \mathrm{MWh}$ "gray" thermal generation, so $\mathrm{LMP}_{\mathrm{N}}=\$ 100 / \mathrm{MWh}$ at $\mathrm{N}$;

2) to meet an additional MW of demand at W, we would dispatch an additional MW of $\$ 50 / \mathrm{MWh}$ "white" thermal generation, so $\mathrm{LMP}_{\mathrm{W}}=\$ 50 / \mathrm{MWh}$ at $\mathrm{W}$;

3) to meet an additional MW of demand at M, we would dispatch an additional MW of \$20/MWh "green" wind generation, so $\mathrm{LMP}_{\mathrm{M}}=\$ 20 / \mathrm{MWh}$ at $\mathrm{M}$.

Because of these prices, the "green" wind is paid $\$ 20 / \mathrm{MWh}$ and the "red" wind is paid $\$ 50 / \mathrm{MWh}$. These outcomes are shown in Fig. 5.

\section{EFFECT OF PRODUCTION TAX CREDITS AND RENEWABLE ENERGY CREDITS}

U.S. Federal production tax credits (PTCs) and state renewable energy credits (RECs) are subsidies to renewable generation that only accrue when the renewable resource is actually generating. That is, they are paid on a per MWh basis as a subsidy "outside" the market. Internationally, there are various mechanisms to provide subsidies to wind and other renewables. For example, there is a somewhat different mechanism in Spain. Moreover, new wind development in the U.S. is likely to elect to receive investment tax credits (ITCs), rather than PTCs. The discussion that follows will focus on the effect of PTCs. These subsidies are presumably aimed at supporting the capital expenditures to develop renewable generation, recognizing that energy market prices alone (or energy and capacity market prices alone, in the case of 
jurisdictions with capacity markets [14]-[16]) are insufficient to support investment in renewables.

Since the "green" wind farms are not fully dispatched, they are foregoing some of the subsidies. In general, to get preference in the ISO dispatch process, the wind farm must reduce its offer price. For example, if one of the "green" wind farms at M dropped its offer below \$20/MWh then the lowest price offer would be fully dispatched. However, the other "green" wind farms could also reduce their offer prices and the question arises as to what offer prices would result. In general, estimating the resulting equilibrium price requires a model of competitive interaction, which has a host of assumptions [17]. Nevertheless, we will estimate a bound on the resulting nodal price at $\mathrm{M}, \mathrm{LMP}_{\mathrm{M}}$, using information about the value of PTCs and RECs and the variable operation and maintenance costs.

PTCs involve a tax credit. All other costs and prices in this paper are effectively quoted in pre-tax dollars. To translate the tax credit into the equivalent value in pre-tax dollars, we must consider the change in pre-tax earnings that would be equivalent to the tax credit. The following analysis paraphrases appendix B of [18]. Suppose that the tax rate is $t$ and that an entity has $k$ dollars of pre-tax earnings, resulting in $(1-t) k$ of after-tax earnings. Now suppose that the tax bill was reduced by a tax credit of $l$. That is, the after-tax earnings would change to $(1-t) k+l$, which is equivalent to earning $[(1-t) k+l] /(1-t)$ pre-tax, a change in pre-tax earnings of $l /(1-t)$. In particular, if the PTC is approximately $\$ 20 / \mathrm{MWh}$ and the tax rate is approximately $t=33 \%$ then the pre-tax value of the PTCs is approximately \$30/MWh.

RECs add a further subsidy to wind production of around $\$ 5 / \mathrm{MWh}$ to $\$ 10 / \mathrm{MWh}$. Table 8.2 of [19] gives a value of $\$ 0 / \mathrm{MWh}$ for variable operation and maintenance costs for wind, but for the purposes of example, we will assume \$5/MWh.

Putting these estimates together, suppose that the total value of PTCs and RECs is $\$ 35 / \mathrm{MWh}$ and that the variable operation and maintenance costs of the wind farm are on the order of $\$ 5 / \mathrm{MWh}$. If a quantity $q$ is sold by a wind farm at the price $\mathrm{LMP}_{\mathrm{M}}$ then the operating profit will be

$$
\left(\mathrm{LMP}_{\mathrm{M}}-\$ 5 / \mathrm{MWh}+\$ 35 / \mathrm{MWh}\right) \times q .
$$

The operating profit is only positive if $\mathrm{LMP}_{\mathrm{M}}>\$ 5 / \mathrm{MWh}-$ $\$ 35 / \mathrm{MWh}=-\$ 30 / \mathrm{MWh}$. As noted, with limited transmission, the $\mathrm{LMP}_{\mathrm{M}}$ at $\mathrm{M}$ is set by the highest accepted wind offer at M. Consequently, if there is intense competition, wind farms may undercut each other, decreasing the highest accepted offer price. That is, the price to the wind farms, $\mathrm{LMP}_{\mathrm{M}}$, could drop as low as minus $\$ 30 / \mathrm{MWh}$.

Although negative prices seem counter-intuitive from the context of typical commodity markets, the inability to dispose of electricity without cost means that negative prices are possible. Moreover, such prices have been observed in the ERCOT balancing market in the West Zone, as shown in Fig. 6 for a particular day in 2009. These negative prices can be interpreted as a transfer from U.S. taxpayers to the market for taking wind power at unfavorable locations. Instead of the subsidies supporting the capital expenditures to develop wind, the subsidies are compensating the market for unfavorable
ERCOT balancing market prices, March 7, 2009, US $\$ / M W h$.

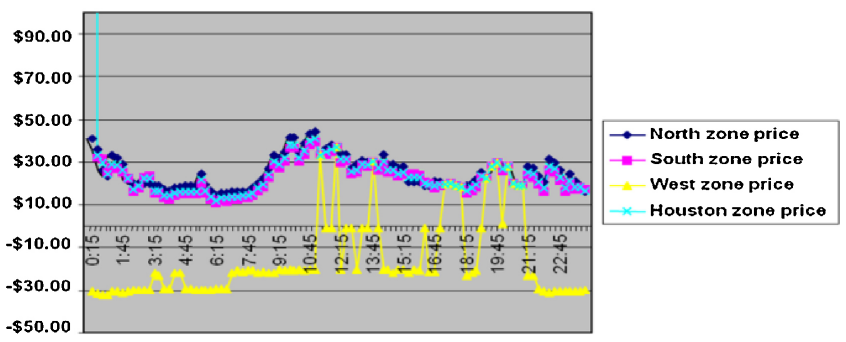

Fig. 6. Prices in ERCOT balancing market. Source: [20].

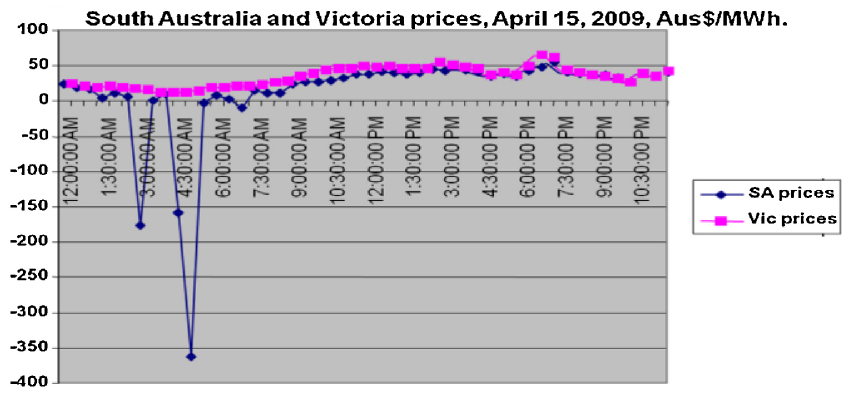

Fig. 7. Prices in the Australian market. Source: [21].

production locations. This circumstance occurred for over $1200 \mathrm{~h}$ in total in 2008 , involving 489415 -min intervals. There were 3069 negative price intervals in 2009 and 4445 negative price intervals in 2010 (from January 2010 until the beginning of the nodal market in December 2010), but only 76 negative price intervals in 2006 and 338 in 2007 [20].

This situation is not restricted to the ERCOT market. Although details about subsidy mechanisms to renewables and market operation are different in the Australian market, there is analogous experience in the South Australia and Victoria "zones" of the Australian market: South Australia is rich in wind resources, but has low peak demand, whereas Victoria has much higher demand. There is limited transmission capability from South Australia to Victoria. As shown in Fig. 7, prices have also been negative in South Australia due to wind.

\section{TRANSMission PRICE RISK AND TRANSMISSION CONSTRUCTION}

Differences in the zonal (or nodal) prices represent the (short-term) opportunity cost to transmit power from one location to another in the constrained system. When the transmission constraints bind, the opportunity cost (and therefore transmission price) can be high. For example, the opportunity cost can be as high as $\$ 40 / \mathrm{MWh}$ or more from the West Zone to demand centers in ERCOT, and higher between South Australia and Victoria in Australia.

The risk of high transmission prices can be hedged by financial instruments issued by the ISO. However, the purchase price for financial instruments should reflect the average expected values of the prices being hedged, so market participants are still exposed to the opportunity cost or its expectation.

In the longer term, investment in transmission can increase the capacity to transmit power and therefore reduce the 
Load-duration without wind. Net Load-duration with wind. Net load = load minus wind.

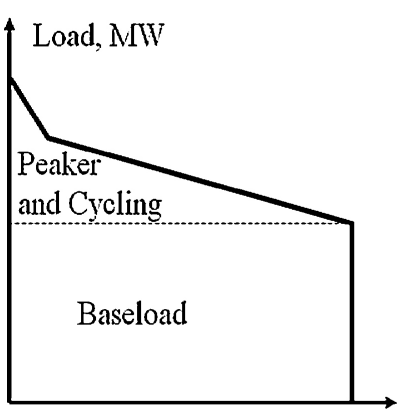

Duration

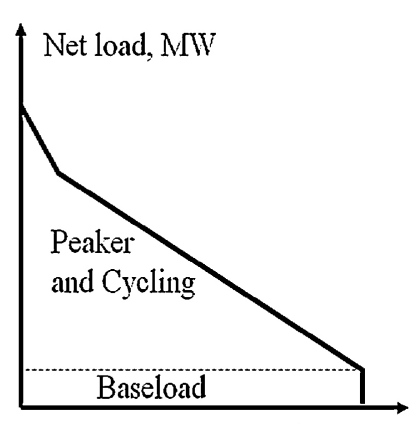

Duration
Fig. 8. Load-duration and net load-duration.

short-term transmission prices. In principle, socially optimal investment to bring energy from remote generation resources would trade off the cost of new transmission (and new wind generation) against the production cost savings (possibly including the cost of greenhouse emissions) and capital deferment of thermal generation. In practice, production cost savings can only be roughly estimated from offers, and transmission planning may be driven by many goals.

Moreover, on-shore wind is typically far from demand in the U.S. and Australia and transmission constraints often limit transfers from wind to demand centers, as in West Zone wind in ERCOT and South Australian wind in Australia. Therefore, transmission capacity increases require more investment for wind than for typical thermal generation.

In the context of ERCOT, the competitive renewable energy zones (CREZ) involve about U.S.\$5 billion in transmission investment to increase export capability from the West Zone. Prior to the construction of the CREZ transmission, about 7 GW of West Texas wind capacity could be accommodated without significant curtailment, after various relatively inexpensive upgrades were carried out in the West Zone. The CREZ will allow for a total of around $18 \mathrm{GW}$ of West Texas wind with a very low level of transmission-related curtailment, corresponding to an increase in export capability from the West Zone of approximately $11 \mathrm{GW}$ [22]. Given an optimistic $40 \%$ capacity factor for wind and rates of return on and of regulated investments such as transmission that would result in a capital cost recovery factor of at least $15 \%$, the transmission for $11 \mathrm{GW}$ of incremental wind in ERCOT can be expected to cost approximately U.S.\$20/MWh or more on average.

It is expected that the ERCOT CREZ transmission upgrades will be completed over the next few years and more wind generation will be built, resulting in much more wind production overall. However, West Texas wind is anti-correlated with ERCOT demand since the wind tends to blow more in winter, spring, and autumn than in summer and more during offpeak hours than on-peak, whereas peak demand in ERCOT is driven by air-conditioning, particularly in summer. This is the typical case for on-shore wind in the U.S., but it should be noted that off-shore wind and solar have better correlation with demand.

The left panel of Fig. 8 shows a load-duration curve that illustrates the distribution of load over a year. The right panel shows the corresponding distribution of the difference between load and wind, which is called the net load. As can be seen in Fig. 8, the peak of the net load is typically nearly as high as the peak of the load, representing the fact that the wind tends not to blow on-peak. On the other hand, the minimum of the net load-duration curve is considerably lower than the minimum of the load-duration curve, reflecting off-peak wind production.

Off-peak wind production tends to decrease the need for thermal generation off-peak. Therefore, if there is intense competition off-peak, prices may be set negative by wind even without transmission constraints. This concurs with recent experience in the ERCOT balancing market as shown in Fig. 9, where prices during the early hours of a day between 2:00 am and 5:30 am were negative throughout ERCOT, not just in the West Zone. (Prices later in the day were negative in the West Zone, but positive elsewhere in ERCOT, reflecting transmission constraints.)

The occurrences of negative prices throughout ERCOT represent a transfer from taxpayers to the market for taking wind power at unfavorable times. A serious policy implication is the potential that additional wind at these times may not be significantly decreasing fossil fuel use and may not be significantly decreasing emissions, undercutting the fundamental policy driver for increased wind power.

The suggestive evidence for the potential lack of significant decrease in emissions with increasing wind is that thermal generation throughout ERCOT is also being exposed to these negative prices at the margin. That is, the thermal generation is paying for its fuel and also paying to produce electricity. Reduced production by thermal generation at these times would save the thermal fuel cost and also avoid the payment by the thermal generation to the electricity market. Consequently, the choice by the thermal generators to not further reduce production at these times is indicative that the alternatives were, on net, even more expensive than paying for fuel and paying the electricity market. For example, it may be that generators operating at minimum production limits would not significantly save on fuel costs if they were to operate at lower levels or to "de-commit" and restart later. If there were increased wind, then forcing the thermal to operate at lower levels or to de-commit could therefore possibly result in very limited savings of fossil fuel and very limited reductions of emissions. Evidence of such situations in Colorado and ERCOT is presented in [23].

Negative prices throughout ERCOT occurred for 116 intervals in 2008, 130 intervals in 2009, but not at all in 2010. While this is suggestive of only a modest and variable effect currently, with increasing wind generation and increased transmission capability, the phenomenon of negative prices throughout ERCOT can be expected to become much more common, as will be discussed in the next section in the context of renewable portfolio standards.

\section{WIND AND DEMAND CORRELATION AND INTERMITTENCY}

The negative prices result, in part, from the difficulty of forecasting when there will be significant wind and responding 


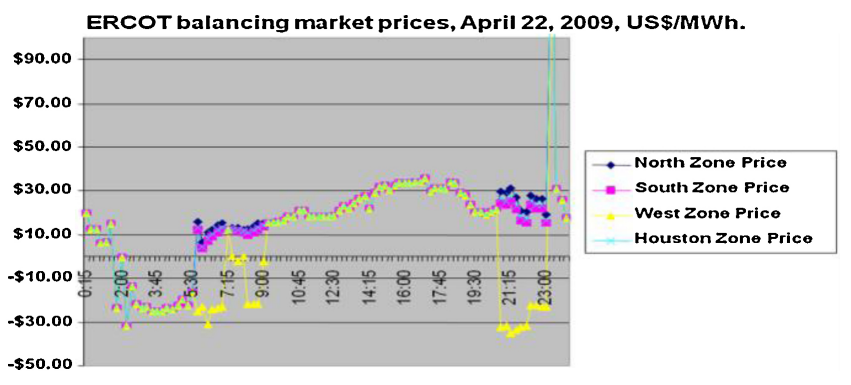

Fig. 9. Negative prices throughout ERCOT in early morning. Source: [20].

to that by reducing or de-committing the thermal generation. If off-peak wind levels can be anticipated in the forecast, centralized "unit commitment" could reduce wind curtailment by decommitting thermal. The Spanish and Australian markets do not and the ERCOT zonal market did not have centralized unit commitment. However, the ERCOT nodal market, which began in December 2010, has centralized unit commitment [24]. It might also be better to deliberately spill more wind under some circumstances; that is, to have more economic curtailment of wind. In the longer-term, the thermal generation portfolio might adapt to "peakier" net load by increasing the fraction of peaker and cycling capacity. This is illustrated in Fig. 8 by the division into baseload, and peaking and cycling. The right panel, with wind, shows less need for baseload and more need for peaking and cycling generation than in the left panel.

The intermittency of wind exacerbates this situation, since electricity demand and supply must be matched essentially continuously. This matching is achieved at various timescales:

1) short-term, by adjustment of generation resources in response to system frequency, through "governor action" and "regulation" ancillary service;

2) medium-term, through offer-based economic dispatch of resources to match average demand over 5,15 , or $60 \mathrm{~min}$ intervals in organized markets and to acquire reserves;

3) long-term, through capacity expansion.

In particular, meeting demand involves more than just the load-duration and net load-duration issues illustrated in Fig. 8. Historically:

1) demand for energy has been considered mostly uncontrollable (but somewhat predictable), while;

2) generation has been controllable (and mostly predictable).

However, wind generation is intermittent and uncontrollable at various timescales. A way to think about this characteristic is to consider wind to be "negative demand." Moreover, analogously to the situation with demand itself, integration of wind involves more than just net load-duration issues. Intermittency of wind imposes requirements for additional ancillary services:

1) short-term, increased regulation;

2) medium-term, increased reserves and utilization of thermal resources with ramping capability;

3) longer-term (as regulation, reserve, and ramping capabilities of the existing thermal generation portfolio become fully utilized), additional flexible thermal resources, storage, or controllable demand.
Furthermore, increasing penetration of wind means less controllable generation resources may be on-line to provide ancillary services and less inertia in the system. The thermal resources that are on-line will operate at lower fractions of capacity; will be required to ramp more; and will operate more sporadically, with possibly worsened efficiencies and emissions [23], a larger range of prices from off-peak to on-peak in energy-only markets, and an even greater trend away from baseload to peaker than based on net load-duration characteristics alone.

Various U.S. studies have estimated the "wind integration" AS costs, with estimates varying from a few to around five U.S.\$/MWh [25]. This variation in estimates reflects:

1) variation in particular of systems;

2) lack of standardization in estimating costs;

3) lack of representation of intermittency in standard generation analysis tools.

As a proxy upper bound to energy-related AS costs, we will consider the capital cost of lead-acid battery based energy storage of around $\$ 50 / \mathrm{kWh}$, divided by the number of charge-discharge cycles of energy over its lifetime of around 1000 cycles, which results in a cost of around U.S.\$50/MWh.

This proxy storage cost cannot be directly translated into an AS cost for wind. For example, requirements for increased resources due to intermittency can be reduced by deliberately spilling wind to:

1) operate at below wind capability to enable contribution of "inertia" and regulation;

2) ramp from one power level to another at limited rate.

However, since wind turbine costs are primarily capital, spilling and limited ramps will increase the cost of wind power. Nevertheless, aggressive portfolio standards in the $20 \%$ to $30 \%$ range for energy will almost certainly involve significant changes in operations of both wind and thermal to cope with intermittency. For example, assuming all renewables are wind and:

1) $30 \%$ renewable portfolio standard by energy;

2) $40 \%$ wind capacity factor (ratio of average production to wind capacity);

3) $55 \%$ load factor (ratio of average to peak demand);

4) ignoring curtailment.

Wind capacity would be $41 \%$ of peak demand and would exceed minimum demand. That is, in the absence of significant storage, there would be zero or negative prices off-peak during high wind periods.

In the particular case of ERCOT, since ERCOT peak demand is about $65 \mathrm{GW}$ [26], a $30 \%$ renewable portfolio standard for energy would require over $26 \mathrm{GW}$ of wind capacity. However, even with up to $10 \mathrm{GW}$ of wind capacity in ERCOT, prices have occasionally been negative during off-peak in spring in ERCOT, with minimum demand around $25 \mathrm{GW}$. With over $26 \mathrm{GW}$ of wind, there would need to be major changes in: operations, portfolio of generation, storage, and demand. There are multiple possible changes to accommodate intermittency, including:

1) increased reserves; 
2) relatively more flexible and agile peaking and cycling generation;

3) wind spillage, provision of inertia, and regulation;

4) energy storage, including compressed-air energy storage;

5) controlled charging of millions of plug-in hybrid vehicles;

6) using off-peak coal generation to power carbon dioxide separation and sequestration.

It is therefore difficult to estimate the capital and operating cost of an optimal portfolio of changes to cope with intermittency. However, as a rough ballpark proxy for energy-related AS cost due to intermittency we will suppose that lead-acid battery storage for $20 \%$ of wind energy production would compensate for intermittency. That is, intermittency would add $20 \%$ times U.S. $\$ 50 / \mathrm{MWh}=$ U.S. $\$ 10 / \mathrm{MWh}$ to cost of wind. This ballpark estimate compares to estimates of up to U.S.\$5/MWh from integration studies [25].

\section{Cost OF REDUCING CARBon EMISSIONS WITH WIND}

This section will combine the various estimates of utilizing wind in order to estimate the cost of using wind to reduce carbon dioxide emissions. Some caution is in order in using these estimates, since, for example:

1) ERCOT charges most costs of transmission construction to demand;

2) North American markets generally charge all AS costs to demand, regardless of cause.

Nevertheless, we will add the wind-related transmission and wind-related AS costs to the cost of wind power. To be clear, this suggests the need for care when comparing to similar figures for other generation assets, particularly given other subsidies in the electricity sector and the fact that transmission construction costs and AS prices are not directly reflected in wholesale prices for energy.

The typical unsubsidized cost of wind energy is around U.S. $\$ 80 /$ MWh, based on a capital cost of around $\$ 1900 / \mathrm{kW}$ [19], $40 \%$ capacity factor for wind, and $15 \%$ cost recovery factor. As discussed previously, we estimate:

1) U.S.\$20/MWh incremental transmission for wind in ERCOT;

2) U.S. $\$ 5 / \mathrm{MWh}$ to U.S. $\$ 10 / \mathrm{MWh}$ proxy to cost of intermittency.

This results in a total of about U.S.\$105/MWh to U.S.\$110/MWh for wind, and should be compared to an average balancing energy market price in ERCOT of around U.S. $\$ 50 / \mathrm{MWh}$ to $\$ 60 / \mathrm{MWh}$ in recent years [20]. The ERCOT energy prices also partially reflect capital costs through high "scarcity prices" during some on-peak periods and so provide a proxy to the market price for both thermal energy and capacity. Based on this proxy to the thermal costs, using wind to displace thermal generation in ERCOT adds about U.S.\$50/MWh to costs. The total annual ERCOT retail energy sales are around three times $10^{8} \mathrm{MWh}$, with a retail bill around U.S. $\$ 30$ billion. Therefore, to achieve $30 \%$ renewable energy from wind would increase the retail bill by very roughly 0.3 times 3 times $10^{8} \mathrm{MWh}$ times $\$ 50 / \mathrm{MWh}$ or about U.S. $\$ 4.5$ billion additional per year.
To put this cost in the context of expectations for reducing carbon dioxide emissions, the United States Congressional Budget Office estimates $\$ 15$ per metric ton of $\mathrm{CO}_{2}$ emissions (\$13-14 per U.S. ton) as an initial price for emissions allowances under House Bill 2454, with prices rising to around \$25/U.S. ton in 2019 [27, Table 3]. Assuming a $10000 \mathrm{Btu} / \mathrm{kWh}$ heat rate, a little over 1 U.S. ton of $\mathrm{CO}_{2}$ is produced per $\mathrm{MWh}$ of coal-fired electricity production, with considerably lower emissions per MWh for gas-fired production of around 0.5 U.S. ton of $\mathrm{CO}_{2}$ per MWh. Since gas is the marginal resource in ERCOT for much of the time, the average marginal emission rate in ERCOT is less than 1 U.S. ton of $\mathrm{CO}_{2}$ per MWh of electricity production. That is, less than $\$ 15$ to $\$ 25$ of $\mathrm{CO}_{2}$ is produced per $\mathrm{MWh}$ of electricity production in ERCOT, given House Bill 2454 valuations of emissions allowances.

We first observe that the negative ERCOT prices for wind suggests that, some of the time, new wind may not even be significantly decreasing greenhouse emissions. However, even assuming that wind displaces 1 U.S. ton of $\mathrm{CO}_{2}$ per $\mathrm{MWh}$ of wind generation, wind is not "worthwhile" for reducing greenhouse emissions given House Bill 2454 values of $\mathrm{CO}_{2}$, since the cost of using wind to displace thermal generation is effectively \$50/U.S. ton of $\mathrm{CO}_{2}$. Given more realistic ERCOT emissions rates, the cost of using wind to displace greenhouse emissions is well over $\$ 50 /$ U.S. ton of $\mathrm{CO}_{2}$.

\section{CONCLUSION}

This paper considered offer-based economic dispatch in U.S. markets, focusing on the real-time market using a simple example with wind that incorporated transmission limitations. The effect of production tax credits and renewable energy credits was considered, and the implications of transmission price risk, wind and demand correlation, and intermittency were considered to develop cost estimates for using wind to reduce carbon dioxide emissions.

Public policy aimed at encouraging renewables, particularly wind, has been very successful in the United States and elsewhere. While this policy has likely reduced greenhouse emissions on average, the policy has achieved these reductions indirectly through displacing thermal generation. Going forward, there is a significant concern that increased displacement of thermal generation might not significantly further reduce production of greenhouse gases. Even if greenhouse emissions are avoided by wind generation, the cost of achieving the reductions, given current wind, transmission, and integration costs, are high. Renewables are often advanced as fulfilling a number of goals, including but not limited to mitigating greenhouse emissions. However, given the considerable reserves of coal and natural gas in countries such as the United States and Australia and given the high cost of using wind to displace thermal generation, there is a timely and serious need to reconsider this policy.

\section{ACKNOWLEDGMENT}

The author would like to thank G. Gülen of the Center for Energy Economics, University of Texas, Austin, for 
discussions during the course of this paper and for assistance in some of the calculations in Section IV.

\section{REFERENCES}

[1] S. Stoft, Power System Economics: Designing Markets for Electricity. Piscataway, NJ: IEEE Press/Wiley Interscience/Wiley, 2002.

[2] PJM Interconnection. (2010, Aug.). Markets and Operations [Online]. Available: http://www.pjm.com/markets-and-operations.aspx

[3] ISO New England, Inc. (2010, Aug.). Markets [Online]. Available: http: //www.iso-ne.com/markets/index.html

[4] New York ISO. (2010, Aug.). Understanding the Markets [Online]. Available: http://www.nyiso.com/public/about_nyiso/understanding_the - markets/index.jsp

[5] Midwest ISO. (2010, Aug.). Midwest Market [Online]. Available: http: //www.midwestiso.org/page/Market $\ \% 20$ Info

[6] California ISO. (2010, Aug.). Operating Procedures: Market Operations [Online]. Available: http://www.caiso.com/thegrid/operations/ opsdoc/marketops/index.html

[7] Southwest Power Pool, Inc. (2010, Aug.). Market Information [Online]. Available: http://www.spp.org/section.asp?pageID=3

[8] ERCOT, Inc. (2010, Aug.). Market Rules [Online]. Available: http:// www.ercot.com/mktrules

[9] Red Eléctrica de España. (2010, Aug.). System Operation [Online]. Available: http://www.ree.es/ingles/operacion/operacion_sistema.asp

[10] Australian Energy Market Operator. (2010, Aug.). Market and Power Systems [Online]. Available: http://www.aemo.com.au/electricityops/ market.html

[11] R. Baldick and H. Niu, "Lessons learned: The Texas experience," in Electricity Deregulation: Choices and Challenges, J. M. Griffin and S. L. Puller, Eds. Chicago, IL/London, U.K.: University of Chicago Press, 2005.

[12] ERCOT. (2010, Aug.). Understanding: Texas Nodal Market Implementation [Online]. Available: http://nodal.ercot.com/about/kd/ understandingNoda1012308.pdf

[13] Australian Energy Market Operator. (2010, Aug.). Operating Procedure [Online]. Available: http://www.aemo.com.au/electricityops/ so_op3709v029.pdf

[14] PJM Interconnection. (2010, Aug.). Reliability Pricing Model [Online]. Available: http://pjm.com/markets-and-operations/rpm.aspx

[15] ISO New England, Inc. (2010, Aug.). Forward Capacity Market (FCM) Frequently Asked Questions [Online]. Available: http://www.isone.com/support/faq/fwd_cap_mkt/index.html

[16] New York ISO. (2010, Aug.). The Capacity Market [Online]. Available: http://www.nyiso.com/public/about_nyiso/understanding_the _ markets/capacity_market/index.jsp
[17] R. Baldick, "Uses of market equilibrium models," in Computing the Electricity Market Equilibrium, X.-P. Zhang, Ed. New York: IEEE Press/Wiley, 2009.

[18] B. Owens. (2002, Apr.). An Economic Valuation of a Geothermal Production Tax Credit [Online]. Available: http://www.nrel.gov/docs/ fy02osti/31969.pdf

[19] Department of Energy, Energy Information Administration. (2010, Apr.). Electricity Market Module [Online]. Available: http://www.eia.doe.gov/ oiaf/aeo/assumption/pdf/electricity.pdf\#page $=3$

[20] Electric Reliability Council of Texas. (2010, Aug.). Balancing Energy Services Market Clearing Prices for Energy Annual Reports [Online]. Available: http://www.ercot.com/mktinfo/prices/mcpe

[21] Australian Energy Market Operator. (2010, Aug.). Price and Demand Data Sets [Online]. Available: http://www.aemo.com.au/data/price_ demand.html

[22] D. Woodfin. (2008, Apr.). CREZ Transmission Optimization Study Summary [Online]. Available: http://www.ercot.com/content/meetings/ board/keydocs/2008/B0415/Item _6_-_CREZ_Transmission_Report -to_PUC_-_-Woodfin_Bojorquez.pdf

[23] Bentek Energy, LLC. (2010, Apr.). How Less Became More...Wind, Power and Unintended Consequences in the Colorado Energy Market [Online]. Available: http://www.wind-watch.org/documents/wp-content/ uploads/BENTEK-How-Less-Became-More.pdf

[24] Electric Reliability Council of Texas. (2010, Aug.). Protocol LibraryNodal [Online]. Available: http://www.ercot.com/mktrules/nprotocols/ lib

[25] M. Milligan. (2006, Aug.). Wind Integration Cost and Ancillary Service Impacts [Online]. Available: http://apps1.eere.energy.gov/ tribalenergy/pdfs/course_wind_milligan1.pdf

[26] Electric Reliability Council of Texas. (2010, Aug.). ERCOT Blasts Through Electricity Demand Record Again [Online]. Available: http:// www.ercot.com/news/press_releases/2010/nr-08-16-10

[27] United States Congressional Budget Office. (2009, Jun.). Cost Estimate, H.R. 2454, American Clean Energy and Security Act of 2009 [Online]. Available: http://www.cbo.gov/ftpdocs/102xx/doc10262/hr2454.pdf

Ross Baldick (F'07) received the B.Sc. degree in mathematics and physics and the B.E. degree in electrical engineering from the University of Sydney, Sydney, Australia, and the M.S. and Ph.D. degrees in electrical engineering and computer sciences from the University of California, Berkeley, in 1988 and 1990, respectively.

From 1991 to 1992, he was a Post-Doctoral Fellow with the Lawrence Berkeley Laboratory, Berkeley, CA. In 1992 and 1993, he was an Assistant Professor with the Worcester Polytechnic Institute, Worcester, MA. He is currently a Professor with the Department of Electrical and Computer Engineering, University of Texas, Austin. 